\title{
Could an online or digital aid facilitate discussions about sexual health with older Australians in general practice?
}

Sue Malta, Meredith Temple-Smith, Jesse Hunter, Declan McGavin, Jenni Lyne, Adrian Bickerstaffe, Jane Hocking

\section{Background and objectives}

Older patients want to discuss sexual health with general practitioners (GPs) but feel uncomfortable doing so, as do their GPs. Online and digital aids (ODAs) are used in other clinical contexts and could provide an effective tool to overcome this discomfort. The aim of this study was to explore health practitioners' views on the type of ODA that could be used to facilitate sexual health discussions between older patients (aged $\geq 60$ years) and health practitioners.

\section{Methods}

Thirty-seven interviews were conducted in Victoria, Australia, between March and June 2017. Participants comprised 15 GPs, 12 practice nurses or practice managers and 10 key informants (five in sexual health, five in ODAs).

\section{Results}

Most ODAs currently available target younger populations. Checklists or self-service kiosks may provide effective means to facilitate sexual health discussions with older patients in primary care.

\section{Discussion}

ODAs are acceptable and feasible to implement in younger populations but need testing with older patients. Health professionals need training to deal with sexual health matters arising from using such aids.
MAINTAINING SEXUAL WELLBEING while ageing can improve physical and mental wellbeing ${ }^{1}$ and cognitive abilities, and is important for adults $\geq 60$ years of age; however, it is often overlooked in policy documents and by health practitioners caring for older people. ${ }^{2}$

Australians remain sexually active well beyond the age of 60 years. A recent Australian survey of 2137 males and females aged $\geq 60$ years ( $75 \%$ aged $60-69$ years; $21 \%$ aged $70-79$ years; $4 \%$ aged 80-89 years) found nearly three-quarters were sexually active in the previous year. ${ }^{3}$ However, among sexually active men and women aged $\geq 60$ years, $\geq 50 \%$ reported at least one form of sexual difficulty in the preceding 12 months. ${ }^{4}$ Further, there is evidence that the prevalence of sexually transmissible infections (STIs) is increasing in this age group, with chlamydia and gonorrhoea diagnosis rates increasing by nearly $50 \%$ in the past five years. ${ }^{5}$

Older Australians visit a GP more than 10 times per year, and most have a regular practice, suggesting an established relationship with a GP. ${ }^{6}$ Despite this, there is evidence that when they initiate sexual health or wellbeing discussions with their GPs, they feel their concerns are dismissed..$^{7-9}$ Many GPs do not prioritise older adults' sexual health and rarely initiate such discussions. ${ }^{10,11}$

Tablet-based screening tools and online interactive websites are gaining popularity in facilitating health discussions, particularly for challenging topics. Online risk assessment that includes a screening tool has been used in primary care to improve knowledge, increase condom use $\mathrm{e}^{12}$ and improve reproductive health attitudes and beliefs. ${ }^{13}$ A computer-based electronic tool with additional web-based components was developed to facilitate sexual health discussions with young adults. ${ }^{14}$ However, such interventions have not been investigated among older adults.

In a companion paper, we discussed barriers to the initiation of sexual health discussions by GPs and practice nurses. ${ }^{15}$ Here we report on health practitioners and key informants' views about potential online and digital aids (ODAs), which might facilitate sexual health discussions with older adults aged $\geq 60$ years in general practice.

\section{Methods}

\section{Sample and recruitment}

A purposive sample of primary care practitioners - including GPs, practice nurses (PNs) and practice managers (PMs) - and key informants consisting of sexual health physicians and those who had used or developed healthrelated ODAs was recruited via the Victorian Primary Care Practice-Based Research Network (VicRen), extended professional networks, snowballing and via web searches, using a sampling matrix to ensure a mix of genders, ages and geographic locations within Victoria. The primary care practitioners and key informants will hereafter be referred to collectively as 'health practitioners'.

\section{Data collection}

Semi-structured interviews were conducted face-to-face or by telephone. After obtaining consent, participants 
were asked demographic questions, followed by questions regarding their views of interventions that might facilitate undertaking discussions with older patients about sexual health and safer sex. Questions for key informants focused on the range of ODAs currently available, those that could be adapted for use with older populations, and the feasibility for use in general practice. Key informants with expertise in sexual health were asked whether an intervention could be used specifically for sexual health interventions in older populations. All interviews were digitally recorded and transcribed by the interviewers (JL, DM, JH).

Ethics approval was granted by University of Melbourne Health Sciences Human Ethics Sub-Committee (Approval number: 1647898).

\section{Data analysis}

Summary descriptive statistics were generated from demographic data. Transcriptions were coded using NVivo software. Iterative thematic analysis commenced after the first five interviews to monitor data saturation. Random interviews were independently coded by MTS. Team consensus was reached on themes identified deductively and inductively.

\section{Results}

\section{Study sample}

Thirty-seven health practitioners were interviewed (Table 1): 15 GPs (eight males, seven females), six PNs (all female) and six PMs (one male, five females); interviews were also conducted with 10 key informants, five of whom had experience in ODAs, three with experience in sexual health, and two with experience in both areas. An overview of key informants and their relevant expertise is shown in Table 2; age and gender are not reported to ensure confidentiality.

The themes identified included:

- potential resources to help initiate sexual health discussions

- design considerations of potential resources

- the impact of resource use.

\section{Potential resources to help initiate sexual health discussions}

Primary care practitioners (GPs, PNs and PMs) were asked to consider what might be an effective resource for facilitating sexual health communication. Responses indicated a range of possibilities:

\section{I have had other posters and other handouts and things in the waiting room that have triggered conversations. GP8}

Generally, it was felt that multimedia displays were now common and effective as interventions, as they offered passive viewing:

\section{We try not to put posters up ... a lot of people don't read them. We have the community health channel screens [on] in our waiting rooms. PM6}

\section{I think a little cartoon on sexual health in the elderly ... if it's very respectfully done, I'd certainly let it play in our waiting room. PN4}

A checklist approach was also discussed, in the form of something that nurses could use when completing health assessments and care plans with older patients. This would allow more time to explore specific concerns and raise the possibility of a GP referral, if needed:

You can just slip [the issue of sexual health] in there with diet, exercise, that sort of stuff. When it's part of a checklist I suppose, it's an easy thing [to do]. GP1

Supporting this view, PMs argued that to be eligible to receive incentive payments from the government, digitalisation of patient notes is now essential to show improvements in health outcomes at a population level.

Key informants proposed that a range of ODAs, such as interactive websites, web app tools and self-completed tabletbased checklists, could be implemented as sexual health interventions with older patients, as they offer relative anonymity. Key informants also anticipated this anonymity would encourage older patients to respond more accurately than they would in face-to-face consultations:

A large barrier to STI testing was found to be embarrassment and fear of judgement ... it stands to reason that people would be more likely to disclose truthfully if those barriers were removed. KI5

Two key informants (KI6, KI7) spoke of their current use of electronic kiosks, such as those used at patient check-in, to guide patients through recording their sexual health histories:

[The sexual health history is conducted] $100 \%$ by the tool. The only thing that happens with the clinician later is if there is an abnormality, or something doesn't look right, then it's clarified. KI6

The [computer-assisted-self-interview] rarely generates any problems in terms of people being reluctant to use it or opting out. KI7

Other key informants emphasised the need for an ODA to be non-judgemental and avoid presumptions about a patient's sexual activity. Further, the outcomes would need to be normalised so that patients did not feel outside the norm for either being, or not being, sexually active.

\section{Design considerations of potential resources}

Several participants questioned whether older adults would be comfortable with and able to use ODAs. Some described low numbers of older patients using web-based, online services for online consultations (KI1), STI screening (KI3, KI5) and online bookings for consultations (KI4).

\section{You've got around 5\% of [older] patients that utilise online appointments; there's been a very slow uptake ... KI4}

The resounding majority of our patients are under 35, which would, unsurprisingly, indicate that the online medium connects better with young people. KI5

One key informant spoke of using a social media intervention aimed at educating 
patients attending a rural general practice clinic and described positive responses following issues engaging with older populations during early stages of its implementation.

Your older populations, generally speaking, weren't big on social media at that time. KI10
However, the same informant also emphasised that this response might be different now and acknowledged that older adults were more computersavvy and internet-savvy than they once were. In addition, one PM who initially thought older adults would struggle with an iPad-like device in the waiting room, said:

Table 1. Primary care practitioner demographics

\begin{tabular}{lccr}
\hline Characteristics & $\begin{array}{r}\text { General } \\
\text { practitioners }\end{array}$ & $\begin{array}{r}\text { Practice } \\
\text { nurses }\end{array}$ & $\begin{array}{r}\text { Practice } \\
\text { managers }\end{array}$ \\
\hline Gender & 7 & 6 & 5 \\
\hline Female & 8 & 0 & 1 \\
\hline Male & & 1 & 0 \\
\hline Age (years) & 0 & 1 & 1 \\
\hline$<30$ & 6 & 2 & 4 \\
\hline $30-44$ & 7 & 2 & 1 \\
\hline $45-59$ & 2 & & 3 \\
\hline$\geq 60$ & & 3 & 3 \\
\hline Location & 13 & 3 & \\
\hline Urban & 2 & 2 & \\
\hline Rural & & 2 & \\
\hline
\end{tabular}

Specific geriatric training

\begin{tabular}{llll}
\hline None (general medical training only) & 7 & 0 & N/A \\
\hline$<6$ months & 2 & 0 & N/A \\
\hline $6-12$ months & 4 & 0 & N/A \\
\hline$>12$ months & 2 & 0 & N/A \\
\hline
\end{tabular}

\section{Postgraduate geriatric training}

\begin{tabular}{llll}
\hline No specific training & 7 & 0 & N/A \\
\hline Sexual health training & $3^{*}$ & $2^{\dagger}$ & N/A \\
\hline
\end{tabular}

\section{Years in general practice}

\begin{tabular}{llll}
\hline$<5$ & 0 & 2 & 4 \\
\hline $5-10$ & 1 & 3 & 1 \\
\hline $11-20$ & 6 & 1 & 1 \\
\hline $21-40$ & 7 & 0 & 0 \\
\hline 40 & 1 & 0 & 0 \\
\hline
\end{tabular}

*One general practitioner received training related to menopause

${ }^{t}$ Four nurses received Pap smear training

\section{A lot of older people now have mobile phones and have a crack at technology at least. PM5}

In contrast to what they thought, most key informants' actual experience with older patients reflected openness to using most forms of digital and online media, if adapted specifically for them. Key informants commented that if an intervention was easy to use and targeted at older patients, then it could work well:

\section{As long as you make it easy for people to use ... and appropriate for what the group feel comfortable doing. KI9}

Participants generally agreed that online and digital technologies were less of a barrier to patients aged $\geq 60$ years than what was commonly believed:

I think once you make it easy enough for them to use, it could work quite well. But it depends which older you mean, over 60 [years] is not old. I think 90 [years] is old. KI9

Targeting an ODA directly to older patients could help increase their awareness and facilitate uptake and use.

The awareness of the service being there will be key. KI1

Participants reported that self-service kiosks seemed well received by older patients. One key informant, who designed self-check-in kiosks for many clinics and hospitals, spoke of the high uptake of older patients using them.

It's interesting that some of the older patients within a practice actually use our kiosks more. KI4

Another spoke of how a single question could sometimes prompt patients to disclose, and suggested that an intervention did not have to be in-depth or complicated to make a difference.

[A simple question] prompts them to provide information they wouldn't necessarily volunteer ... you can use just 
one question to find out if it's worth investigating further... KI2

An example of such a question might be, 'Would you have any interest in discussing sexual health with a health practitioner?' Such an approach could be simple and useful for facilitating discussion in general practice.

One key informant spoke of the difficulties of getting clinical staff to use an intervention designed specifically for them.

The problem with the tool is the age-old problem with anything like this - which is trying to get the GP to actually use it. KI2

Other key informants highlighted that changes in practice may require administrative staff to take on unwelcome additional roles.

The admin staff don't want [an iPad in the waiting room] ... The admin staff are so busy and stressed, they cannot do one more thing. KI2

In addition, some key informants highlighted how clinical staff could be reluctant to relinquish control of patient consultations to interventions such as computer-assisted self-interviews.
Some of the doctors really hate you getting inside the consultations, so they didn't like [the computer-assisted self-interviews]. KI9

\section{The impact of resource use}

Many participants warned that the value of a new resource for facilitating discussions between older patients and health practitioners would be compromised if the health practitioner was uncertain about what to do with the patient afterwards. For instance, one key informant believed that health practitioners did not receive adequate training in treating sexual health in older populations, and that sexual health in general was taught poorly to students and doctors.

The majority of sexual health is looked at by primary healthcare practitioners and I think a lot of them have been ill-equipped to do it well, which I think is a failing of the health education. KI8

Thus, patients did not always receive the appropriate support needed for specific issues; some issues were not addressed at all.

... because they're uncomfortable ... they're doing [a chlamydia test] so it comes back negative ... but when it comes back positive, what do [GPs] actually do? KI8
Many GPs expressed frustration at the lack of detailed sexual health information and resources available for and about older patients. They highlighted limited formal education on sexual health, particularly in relation to older patients, and stated that it mostly focused on sexual dysfunction.

Ifeel there are fewer barriers [about sexual dysfunction rather than sexual health] as that was part of my training and that's what people expect in general. GP2

GPs often did not want the responsibility of raising the topic of sexual health because they felt they did not have the knowledge necessary to adequately deal with sexual health issues in later life. GPs tended to refer to other specialist colleagues as their main resource.

\section{Absence of guidelines and clear treatment protocols for sexual health in older people}

The absence of well-defined procedures and treatments for all aspects of sexual health in later life - even a global understanding of what is considered 'normal' - means there is also a lack of treatment consensus for some sexual health issues faced by older populations.

Table 2. Summary of key informants*

\begin{tabular}{|c|c|c|c|}
\hline Role & Expertise/specialty & $\begin{array}{c}\text { Online and digital aids (ODAs) } \\
\text { designer/user and/or sexual } \\
\text { health (SH) practitioner }\end{array}$ & $\begin{array}{l}\text { Key informant } \\
\text { (KI) }\end{array}$ \\
\hline Medical doctor/founder & Web-based consultation business & ODAs & $\mathrm{KI1}$ \\
\hline Senior research fellow & Digital and online interventions (DOIs) & ODAs & $\mathrm{KI} 2$ \\
\hline Cofounder & Web-based health intervention business & ODAs & $\mathrm{KI} 3$ \\
\hline DOl systems designer & Check-in kiosks and online surveys & ODAs & $\mathrm{K} 14$ \\
\hline Medical doctor/co-founder & Web-based health intervention business & ODAs & $\mathrm{KI} 5$ \\
\hline Nurse & Sexual health interventions using DOls & $\mathrm{SH}$ and ODAs & $\mathrm{KI} 6$ \\
\hline Academic/director & Sexual health centre & $\mathrm{SH}$ & $\mathrm{K} 17$ \\
\hline Medical doctor/academic & Sexual health & $\mathrm{SH}$ & $\mathrm{K} 18$ \\
\hline Academic (public health)/director & Sexual health centre & $\mathrm{SH}$ & $\mathrm{KI9}$ \\
\hline Medical doctor/academic & Social media interventions & SH and ODAs & $\mathrm{KI} 10$ \\
\hline
\end{tabular}

${ }^{*}$ Age and gender not reported to ensure confidentiality 
I think we're actually quite bad at knowing what normal is ... I don't even know that at a professional level [we know] what's normal and what's not ... KI9

The need to normalise sexual health was also observed.

I think, making [sexual health] less taboo. We've got to make it ... part of our general discussion. KI10

\section{Discussion}

Sexual health is a challenging issue because of its delicate and complex nature. ${ }^{16}$ Older patients want the opportunity to discuss sexual health but feel uncomfortable in broaching their concerns themselves ${ }^{9}$ and want their GPs to initiate the discussion in an open but sensitive manner. ${ }^{10}$ However, GPs do not feel comfortable initiating these discussions with older patients. ${ }^{11}$

\section{What format should an ODA for older populations take?}

The common sentiment was that any future intervention targeted at older populations needed to be simple and fit in with the patient flow of the clinic. Some participants had experienced poor uptake of web-based interventions with older patients. This is mirrored in the literature, with studies reporting high attrition rates for online-based interventions. ${ }^{17-19}$ Reasons for poor uptake are not well understood, but lack of involvement of older patients in the intervention design may contribute to this. ${ }^{20}$

Some participants thought older adults may not be comfortable with, or able to use, ODAs; however, data show the proportion of older Australians accessing the internet has steadily increased: $89 \%$ of people aged 65-69 years reported accessing the internet in 2016, compared with $75 \%$ in 2011 ; among people aged $\geq 80$ years, the percentage rose from $48 \%$ in 2011 to $58 \%$ in $2016 .^{21}$ This suggests electronic literacy will continue to improve among older adults over time.

Self-service kiosks appear to be a promising digital intervention for use with older populations and provide several benefits, notably time and cost savings. ${ }^{22}$ However, the impact of patient demographics on interaction/use is not evident in the literature. By contrast, our study found that age was not a barrier to kiosk use. Reasons to account for this include the ubiquity of self-service kiosks, such as at airport check-ins, fast food restaurants, government service centres and, of course, automated teller machines (ATMs). Self-service kiosks in general practice could be adapted to ask older patients to complete a short survey on check-in and could also include screening questions for sexual health. Self-service kiosks are currently used successfully to take in-depth sexual histories with younger population groups.

\section{What would an ODA for older populations involve?}

Emery et al developed and validated a tool consisting of nine yes/no questions for screening family history in primary care. ${ }^{23}$ They found the short, simple questions provided an accurate method to screen for patients requiring further risk assessments. Similarly, other studies have shown the accuracy of using brief screening questionnaires to identify patients at high risk for cardiovascular disease ${ }^{24}$ and multitude of family history risk factors. ${ }^{25}$

Evaluation of short questionnaires to accurately screen for sexual health risk in older adults has not previously been undertaken. They could be used to raise awareness and prompt or promote further discussion, effectively performing the function of an intervention itself, as has previously been suggested for a younger cohort. ${ }^{18}$ We found that healthcare practitioners and key informants believed electronic interventions in a checklist format would be suitable to use with older patients because of ease of use and the anonymity they provide.

\section{Other considerations}

One key informant raised concerns that any intervention would require training for health practitioners in how to deal with the sexual health issues it would raise. This is clearly illustrated in the work of Bauer et al, who found that even when sexual health discussions occurred between older patients and their doctors, patients were still dissatisfied with the treatment and support they received. ${ }^{11}$ Given older patients' sexual health needs differ substantially from younger populations, training needs to be focused on sexual health in later life, not just sexual health more generally.

\section{Interpretation and comparison with existing literature}

Most of the ODAs in use and discussed in this study do not target older populations, consistent with a recent systematic review on sexual health interventions delivered by mobile technologies, none of which targeted later life. ${ }^{26}$ It is difficult to extrapolate from these findings whether older population groups would use mobile technologies to address their sexual health concerns. Nonetheless, key informants interviewed for the present study believed older adults could be reached with ODAs, provided they were designed for - and carefully targeted towards-older populations.

\section{Strengths and limitations}

The strength of this study is that it provides a range of perspectives from GPs, PNs and PMs as well as key informants in sexual health and/or the development/use of ODAs, allowing for triangulation of viewpoints to arrive at a clear and practical vision of an online or digitally implemented sexual health intervention for older patients in primary care. The study is limited in its scope because it was not able to explore the heterogeneity of older adults in terms of factors such as cultural variability and computer literacy.

\section{Conclusion}

Older adults want the opportunity to discuss sexual health matters with their GPs, and ODAs might offer an effective intervention for initiating these conversations. While ODAs have been found to be acceptable and feasible to implement in younger populations, they need to be tested with older patients. We found that any intervention to facilitate 
sexual health discussions in general practice needs to be specifically targeted towards older populations and made relevant for them. Additional support and training for health professionals must also be provided.

\section{Authors}

Sue Malta PhD, Research Fellow, Melbourne School of Population and Global Health, University of Melbourne and Social Gerontology Division, National Ageing Research Institute, Vic. susan.malta@ unimelb.edu.au

Meredith Temple-Smith PhD, Director of Research Training, Department of General Practice, University of Melbourne, Vic

Jesse Hunter MD, Melbourne Medical School,

University of Melbourne, Vic

Declan McGavin MD, Melbourne Medical School,

University of Melbourne, Vic

Jenni Lyne MD, Melbourne Medical School, University of Melbourne, Vic

Adrian Bickerstaffe PhD, Melbourne School of Population and Global Health, University of Melbourne, Vic

Jane Hocking PhD, Head, Sexual Health Unit, Melbourne School of Population and Global Health,

University of Melbourne, Vic

Competing interests: None.

Funding: This study was supported by a grant from the Hallmark Ageing Research Institute, University of Melbourne.

Provenance and peer review: Not commissioned, externally peer reviewed.

\section{Acknowledgements}

The senior authors would like to acknowledge the work undertaken by the three final-year medical students for this project and the key informants who gave up their time to be involved.

\section{References}

1. Lindau ST, Gavrilova N. Sex, health, and years of sexually active life gained due to good health: Evidence from two US population based cross sectional surveys of ageing. BMJ 2010;9(340):c810. doi: 10.1136/bmj.c810.

2. Kirkman L, Kenny A, Fox C. Evidence of absence: Midlife and older adult sexual health policy in Australia. Sex Res Social Policy 2013;10(2):135-48.

3. Lyons A, Heywood W, Fileborn B, et al. The Sex, Age, and Me study: Recruitment and sampling for a large mixed-methods study of sexua health and relationships in an older Australian population. Cult Health Sex 2017:19(9):1038-52. doi: 10.1080/13691058.2017.1288268.

4. Mitchell KR, Mercer $\mathrm{CH}$, Ploubidis GB, et al. Sexual function in Britain: Findings from the third National Survey of Sexual Attitudes and Lifestyles (Natsal-3). Lancet 2013;382(9907):1817-29. doi: 10.1016/S0140-6736(13)62366-1.

5. Department of Health. Number of chlamydia and gonorrhoea notifications 2016. Canberra: DoH, 2016. Available at www.health.gov.au/internet/ main/publishing.nsf/Content/cda-cdi 3904c.htm [Accessed 12 September 2018]

6. Family Medicine Research Centre. Care of older people in Australian general practice. Summary document. Sydney: Family Medicine Research
Centre, 2016. Available at http://sydney.edu. $\mathrm{au} / \mathrm{medicine} / \mathrm{fmrc} /$ publications/BEACHfeature-2015.pdf [Accessed 12 September 2018].

7. Hinchliff S, Gott M. Seeking medical help for sexual concerns in mid- and later life: A review of the literature. J Sex Res 2011;48(2-3):106-17. doi: 10.1080/00224499.2010.548610.

8. Bentrott MD, Margrett JA. Taking a personcentered approach to understanding sexual expression among long-term care residents: Theoretical perspectives and research challenges. Ageing Int 2011;36(3):401.

9. Gott M, Hinchliff S. Barriers to seeking treatment for sexual problems in primary care: A qualitative study with older people. Fam Pract 2003;20(6):690-95

10. Gott M, Galena E, Hinchliff S, Elford H. 'Opening a can of worms': GP and practice nurse barriers to talking about sexual health in primary care. Fam Pract 2004;21(5):528-36. doi: 10.1093/ fampra/cmh509.

11. Bauer M, Haesler E, Fetherstonhaugh D. Let's talk about sex: Older people's views on the recognition of sexuality and sexual health in the health-care setting. Health Expect 2016;19(6):1237-50. doi: 10.1111/hex.12418.

12. Bowen AM, Williams ML, Daniel CM, Clayton S. Internet based HIV prevention research targeting rural MSM: Feasibility, acceptability, and preliminary efficacy. J Behav Med 2008;31(6): 463-77. doi: 10.1007/s10865-008-9171-6.

13. Swartz LH, Sherman CA, Harvey SM, Blanchard J, Vawter F, Gau J. Midlife women online: Evaluation of an internet-based program to prevent unintended pregnancy \& STIs. J Women Aging 2011;23(4):342-59. doi: 10.1080/08952841.2011.613255.

14. Macdowall W, Parker R, Nanchahal K, et al 'Talking of Sex': Developing and piloting a sexual health communication tool for use in primary care. Patient Educ Couns 2010;81(3):332-37. doi: 10.1016/j.pec.2010.10.027.

15. Malta S, Hocking J, Lyne J, et al. Do you talk to your patients about sexual health? Health practitioners' knowledge of, and attitudes towards, management of sexual health among older Australians. Aust J Gen Pract 2018:47(11):807-11. doi: 10.31128/AJGP04-18-4556.

16. Weeks DJ. Sex for the mature adult: Health, self-esteem and countering ageist stereotypes. Sexual Relation Ther 2002;17(3):231-40. doi: 10.1080/14681990220149031.

17. Anderson D, Seib C, McGuire A, Porter-Steele J. Decreasing menopausal symptoms in women undertaking a web-based multi-modal lifestyle intervention: The Women's Wellness Program. Maturitas 2015;81(1):69-75. doi: 10.1016/j. maturitas.2015.02.263.

18. Bailey JV, Webster R, Hunter R, et al. The Men's Safer Sex (MeNSS) trial: Protocol for a pilot randomised controlled trial of an interactive digital intervention to increase condom use in men. BMJ Open 2015;5(2):e007552. doi: 10.1136/bmjopen2014-007552.

19. Suffoletto B, Akers A, McGinnis KA, Calabria J, Wiesenfeld HC, Clark DB. A sex risk reduction text-message program for young adult females discharged from the emergency department. J Adolesc Health 2013;53(3):387-93. doi: 10.1016/j. jadohealth.2013.04.006

20. Wherton J, Sugarhood P, Procter R, Hinder S, Greenhalgh T. Co-production in practice: How people with assisted living needs can help design and evolve technologies and services. Implementation Sci 2015:10:75. doi: 10.1186/ s13012-015-0271-8.
21. Australian Communications and Media Authority. Digital Lives of Older Australians. ACMA. 4 August 2016. Available at www.acma.gov.au/ theACMA/engage-blogs/engage-blogs/Researchsnapshots/Digital-lives-of-older-Australians [Accessed 12 September 2018].

22. Lowe $C$, Cummin D. The use of kiosk technology in general practice. J Telemed Telecare 2010;16(4):201-03. doi: 10.1258/jtt.2010.004011.

23. Emery JD, Reid G, Prevost AT, Ravine D, Walter FM. Development and validation of a family history screening questionnaire in Australian primary care. Ann Fam Med 2014;12(3):241-49. doi: 10.1370/afm.1617.

24. Qureshi N, Armstrong S, Dhiman P, et al. Effect of adding systematic family history enquiry to cardiovascular disease risk assessment in primary care: A matched-pair, cluster randomized trial. Ann Intern Med 2012;156(4):253-62. doi: 10.7326/0003-4819-156-4-20120221000002.

25. Ruffin MT, Nease DE Jr, Sen A, et al. Effect of preventive messages tailored to family history on health behaviors: The Family Healthware Impact Trial. Ann Fam Med 2011;9(1):3-11. doi: 10.1370/ afm.1197.

26. Burns K, Keating P, Free C. A systematic review of randomised control trials of sexual health interventions delivered by mobile technologies. BMC Public Health 2016;16(1):778. doi: 10.1186/ s12889-016-3408-z 